\title{
Extremely low frequency magnetic fields induce oxidative stress in rat brain
}

\author{
Pavan K. Manikonda ${ }^{1,2}$, Pilankatta Rajendra ${ }^{3,4}$, D. Devendranath ${ }^{3}$, B. Gunasekaran ${ }^{3}$, \\ Channakeshava $^{3}$, Shivakumara R. S. Aradhya ${ }^{3}$, Rao B. Sashidhar ${ }^{1}$ and Chivukula \\ Subramanyam ${ }^{1,5}$ \\ ${ }^{1}$ Department of Biochemistry, University College of Science, Osmania University, Hyderabad-500 007, AP, India \\ ${ }^{2}$ Division of Pre-clinical Toxicology, Sugen Life Sciences Pvt. Ltd. Tirupati-517 505, AP, India \\ ${ }^{3}$ Ultra High Voltage Research Laboratory, Central Power Research Institute, Hyderabad-500 039, AP, India \\ ${ }^{4}$ Central University of Kerala, Kasaragod-671 328, Kerala, India \\ ${ }^{5}$ Asian Institute of Gastroenterology, Hyderabad-500 082, AP, India
}

\begin{abstract}
The present investigation was conducted to understand the influence of long-term exposure of rats to extremely low frequency magnetic fields (ELF-MF), focusing on oxidative stress (OS) on different regions of rat's brain. Male Wistar rats (21-day-old) were exposed to ELF-MF $(50 \mathrm{~Hz} ; 50$ and $100 \mu \mathrm{T}$ ) for 90 days continuously; hippocampal, cerebellar and cortical regions from rats were analyzed for (i) reactive oxygen species (ROS), (ii) metabolites indicative of OS and (iii) antioxidant enzymes. In comparison to control group rats, the rats that were continuously exposed to ELF-MF caused OS and altered glutathione (GSH/GSSG) levels in dose-dependent manner in all the regions of the brain. Accumulation of ROS, lipid peroxidation end products and activity of superoxide dismutase in different regions was in the descending order of cerebellum $>$ hippocampus $>$ cortex. Decrement in GSH/GSSG levels and increment in glutathione peroxidase activity were in the descending order of hippocampus $>$ cerebellum $>$ cortex. The continuous exposure to ELF-MF caused OS in all the examined regions of brain more significantly at $100 \mu \mathrm{T}$ than at $50 \mu \mathrm{T}$. Varied influences observed in different regions of the brain, as documented in this study, may contribute to altered metabolic patterns in its related regions of the central nervous system, leading to aberrant neuronal functions.
\end{abstract}

Key words: Central nervous system — Magnetic fields - Oxidative stress - Antioxidant enzymes

Abbreviations: ELF-MF, extremely low frequency magnetic fields; GSH, glutathione (reduced); GSSG, glutathione (oxidized); GPx, glutathione peroxidase; SOD, superoxide dismutase; TBARS, thiobarbituric acid reactive substances.

\section{Introduction}

A variety of central nervous system disorders, such as nervousness, anxiety, sleep disturbances and stress have been reported to occur in human population when exposed

Correspondence to: Rao B. Sashidhar, Department of Biochemistry, University College of Science, Osmania University, Hyderabad500 007, AP, India

E-mail: sashi_rao@yahoo.com to magnetic field (Akerstedt et al. 1998; Jadidi et al. 2007; Funk et al. 2009), which has been attracting increased public interest. Previous epidemiological surveys conducted on human exposure to extremely low frequency (ELF) electromagnetic fields (EMF) have implicated that ELF-EMF causes several health disorders in humans, such as various types of brain cancers, depression and suicide, neurodegenerative, cardiovascular and reproductive diseases (Central Power Research Institute Report 2000; Ahlbom et al. 2001; World Health Organization Report, 2007; Schuz and Ahlbom 2008; 
Kheifets et al. 2009). In addition, alterations in circadian rhythms which cause sleep disturbances have been observed in response to the EMF exposure $(50 / 60 \mathrm{~Hz})$ due to related decrease in melatonin levels (Burch et al. 1999; Davis et al. 2006) and cortical serotonergic neurotransmission (Janac et al. 2009). Since melatonin is an antioxidant and its decrease is concomitant with accumulation of free radicals (PandiPerumal et al. 2013), oxidative stress increases when exposed to EMF, hence supplementation of antioxidants were recommended under these conditions (Zwirska-Korczala et al. 2004; Sokolovic et al. 2008; El-Helaly and Abu-Hashem 2010; Kerman and Senol 2012). Interestingly, the EMF was not only reported to increase the life span of free radicals (Kabuto et al. 2001; Stevens 2004), but was also involved in weakening the antioxidant defense mechanism (Lee et al. 2004; Falone et al. 2008), leading to increased oxidative stress condition (Blank and Goodman 2009; Martinez-Samano et al. 2012). Several earlier studies have suggested that short and long-term exposure to 40-60 Hz ELF magnetic fields (MF) induce oxidative stress on various regions of the rodent's brain such as, cerebellum, hippocampus and striatum (Fu. et.al. 2009; Ciejka et al. 2011; Chu et al. 2011) leading to neurodegeneration causing deficit in learning and memory (Consales et al. 2012; Cui et al. 2012; Foroozandeh et al. 2012). Even though such prior knowledge gained from the epidemiological and experimental studies suggests strong correlation between the EMF exposure and oxidative stress, it is necessary to be acquainted with immense information regarding the oxidative stress on specific regions of the brain due to the magnetic field exposure on whole body of all animals over a long period of time.

In view of the above cited investigations, it is evident that no single study has been definite while evaluating biological effects due to MF exposure (EMF RAPID Program 2004); we have earlier conducted numerous MF exposure studies involving different biological systems that includes in vitro (cell cultures) as well as in vivo (animals, plants and developing embryos) models (Rajendra et al. 2004, 2005, 2012; Manikonda et al. 2007) to obtain holistic information. The magnetic field intensities selected for the present study were based on the data collected from field surveys conducted in India by Ultra High Voltage Research Laboratory of Central Power Research Institute (CPRI), Government of India (Final Technical Report 2000, Identification No. 11.1.11). According to these surveys, the people in India living near transmission lines of voltage rating $132 \mathrm{kV}$ or generating stations are subjected to cumulative exposure in the range of 10 to $100 \mu \mathrm{T}$ over the course of the day, whereas the people working in power-intensive industries with highly loaded substations are exposed to 100-500 $\mu \mathrm{T}$ magnetic fields. However, the laboratory investigation on different biological models at CPRI revealed that a continuous exposure of $20.85 \mu \mathrm{T}$ would mimic the worst case of magnetic field exposures at power-intensive industries. Hence, power line frequency magnetic fields of intensities in the range of 1 to $100 \mu \mathrm{T}$ were chosen for studying the biological effects. Earlier studies on developing chick embryos reported that power line frequency magnetic fields alter neurochemical parameters such as tyrosine, glutamine, norephinephrine levels and the activity of glutamate synthase in developing chick embryos (Rajendra et al. 2004). The studies have also reported that ELF-MF decreased N-methyl D-Aspartic Acid (NMDA) receptor binding affinity and altered calcium signaling enzymes (Manikonda et al. 2007). In continuation of these neurochemical observations, this communication evaluates parameters related to oxidative stress on the hippocampus (associated with learning and memory), cerebellum (responsible for regulation/ coordination of movement and balance) and cortex (involved in higher brain functions of thought and action) in rodent brains exposed to long-term ELF-MF. The present experimental investigation describes the nature of oxidative stress caused by the ELF-MF $(50 \mathrm{~Hz})$ in various neuronal regions of rats.

\section{Materials and Methods}

\section{Magnetic field exposure and experimental model}

Ethical committee approval was obtained from Ministry of Social Justice and Empowerment, Government of India, New Delhi (No.276) for conducting animal experiments described herein. Male Wistar rats (21-day-old, weighing between 50-70 g) were obtained from the National Center for Laboratory Animal Sciences, Hyderabad, India. After one week of acclimatization, weight-matched animals were randomly distributed into three groups ( $n=6$ for each group), viz., Group I: control; Group II: exposed to $50 \mu \mathrm{T}$; Group III: exposed to $100 \mu \mathrm{T}$, for magnetic field $(50 \mathrm{~Hz})$ exposure studies.

All the animals were housed individually in the cages and were covered with stainless steel (SS) mesh lid. The ELF-MF exposed animals housed in cages were continuously exposed to either $50 \mu \mathrm{T}$ or $100 \mu \mathrm{T}$ intensities. The intensities, i.e., $50 \mu \mathrm{T}$ or $100 \mu \mathrm{T}$, inside the cages were confirmed by measuring the intensity using EMDEX LITE, EPRI magnetic field meter (Enertech Consultants, Campbell, CA). The measured intensity was found to be consistent in all the cages. Both ELF-MF exposed and control group animals were within the same housing and shared a common entrance, airflow, temperature $\left(25 \pm 2^{\circ} \mathrm{C}\right)$ and light intensity (ordinary fluorescent light of color temperature, $4100^{\circ} \mathrm{K}$ : $195.9 \pm 8.54$ lux: measured by LUX meter 3816, Germany) with a 12:12 hour light and dark cycles maintained throughout the exposure period. Stock pellet diet (protein 20\%, carbohydrate 60\%, fat $5 \%$, fiber $5 \%$ and vitamin/mineral mixture 5\%) and water were provided ad libitum throughout the experiment. 
The EMF-MF exposure facility consists of 18 wooden bobbins $(0.5 \mathrm{~m} \times 0.5 \mathrm{~m} \times 0.5 \mathrm{~m})$; wherein individual bobbins were wound by two sets of horizontal coils (each set of 25 turns), capable of producing horizontal, vertical, circular and elliptical magnetic fields as described earlier (Rajendra et al. 2005). Individual turns in the horizontal coil were separated by a distance of $5 \mathrm{~mm}$. The coils were made of 22 gauge enameled copper wire and the inductance of the coil was designed to be $4.9 \pm 0.28 \mathrm{mH}$ and $1.4 \pm 0.25 \mathrm{mH}$ for the vertical and horizontal coils, respectively. In both sets of horizontal coils, the same direction was maintained for winding as well as for the flow of current. Similarly, all the three vertical coils arranged were also movable around its position to adjust MF intensity to obtain uniform MF exposure throughout the cage. The coils were connected to a stabilized AC $(50 \mathrm{~Hz})$ power supply $(15 \mathrm{~V})$ through a step-down transformer, thereby reducing the electric field significantly in the exposed area. An uninterrupted power supply (UPS) was used in order to avoid the variations in power supply voltage or limit them to less than $1 \%$ ensuring stable MF generation. The impedance of the coil being constant at fixed frequencies, the current control was achieved through a variable resistance connected in series with the coil. Similarly, so as to reduce heating of conductor of the coil, the conductor diameter used was higher than the needed to carry the necessary current. A distance of $0.3 \mathrm{~m}$ separated the individual bobbins to avoid the interference of the fields originating from the adjacent boxes.

A set up similar to ELF-MF exposed animals, having 18 wooden bobbins were established without energizing the coil for sham control group with enough spacing (2.78 $\mathrm{m}$ between MF-exposed animals and sham controls). The geometric field inside the wooden boxes of control and exposed groups were: $\mathrm{Z}$ (vertical) $=15.894 \pm 0.1418 \mu \mathrm{T}$ and $\mathrm{H}($ horizontal $)=39.43 \pm 0.0131 \mu \mathrm{T}$. After continuous exposure to ELF-MF (50 and $100 \mu \mathrm{T}$ ) for 90 days, the body weight of animals was measured and the animals were sacrificed by cervical decapitation.

\section{Dissection and collection of brain tissues}

After decapitation, the brain was immediately removed and placed on the ice cold metal plate with its dorsal side facing the metal plate. The cerebellum was lifted using forceps, cut at pons and the brain was placed with its ventral side facing the metal plate. Cerebellum was snapped off from colliculus inferior adjoining to cortical lobes and freed from pons and medulla. The mid-brain was removed and discarded. The gray colored translucent hippocampus was distinguished by separating the two cerebral hemispheres along the midline by gently using small forceps and by removing it from pink/yellow colored cortex without damaging it. Both left and right halves of hippocampus was dissected out from the cortex. Further, the cortex (grey and white matter) was col- lected by removing the olfactory lobes, striatum and septum using scalpel and forceps. The dissected out hippocampus, cortex and cerebellum were immediately kept on ice, washed with ice cold phosphate buffered saline (PBS) $50 \mathrm{mM}, \mathrm{pH} 7.4$, blotted on dry filter paper, weighed and collected into Eppendorf tubes. The tissues were frozen in liquid nitrogen and stored at $-80^{\circ} \mathrm{C}$ until further use.

\section{Measurement of reactive oxygen species}

Reactive oxygen species (ROS) in brain tissues were determined using a cell permeable non-fluorescent probe, 2',7'dichlorodihydrofluorescein diacetate (2',7'-DCFDA) as per the method reported by Driver et al. (2000), with minor modifications. Briefly, 10\% homogenate of the brain tissues was prepared in ice cold PBS (50 mM, pH 7.4) using glass-Teflon homogenizer at $4^{\circ} \mathrm{C}$ and homogenates were centrifuged at $1000 \times g$ for $10 \mathrm{~min}$ at $4^{\circ} \mathrm{C}$ to obtain clear supernatants. The reaction mixture $(1 \mathrm{ml})$ containing PBS buffer $(50 \mathrm{mM}$, $\mathrm{pH} 7.4), 0.2 \mathrm{ml}$ homogenate $(100 \mu \mathrm{g}$ protein) and $10 \mu \mathrm{l}$ of 2',7'-DCFDA $(10 \mu \mathrm{M})$ (Molecular Probes, Eugene, USA) was incubated for $30 \mathrm{~min}$ at $37 \pm 1^{\circ} \mathrm{C}$, in the dark. The fluorescence intensity of formed 2',7' - DCFDA upon reaction with ROS was measured at $\lambda_{\mathrm{Ex}}=490 \mathrm{~nm}$ and $\lambda_{\mathrm{Em}}=520 \mathrm{~nm}$ in steady state spectroflourometer (Perkin Elmer LS-50B, Boston, USA). The background fluorescence was corrected by using the reaction mixture without homogenates as blank. Protein content in the homogenates was determined by Bradford's method (1976). The ROS accumulation in each sample was calculated for $100 \mu \mathrm{g}$ protein and expressed as relative fluorescence intensity/100 $\mu \mathrm{g}$ protein.

\section{Estimation of metabolites and antioxidant enzymes}

Cytosolic extracts were isolated from $10 \%$ homogenates of brain regions by employing centrifugation at $15,000 \times g$ for $30 \mathrm{~min}$ at $4^{\circ} \mathrm{C}$ in appropriate buffers: A (50 mM Tris buffer, pH 7.4), B (0.2 M Tris-0.02 M EDTA, pH 8.2), C (50 mM sodium phosphate buffer, $\mathrm{pH} 7.2)$ and $\mathrm{D}(50 \mathrm{mM}$ sodium phosphate buffer, $\mathrm{pH}$ 7.0) for estimation of thiobarbituric acid reactive substances (TBARS), glutathione, superoxide dismutase (SOD) and glutathione peroxidase (GPx) activities, respectively (Manikonda and Jagota 2012).

Products of lipid peroxidation were measured as TBARS in cytosolic extracts prepared in buffer A. To $0.5 \mathrm{ml}$ sample (50 $\mu$ g protein), $0.25 \mathrm{ml}$ of $20 \%$ trichloroacetic acid (TCA) and $0.25 \mathrm{ml}$ of $0.67 \% 2$-thiobarbituric acid (TBA) were added followed by boiling it in water bath for $20 \mathrm{~min}$. The reaction mix was cooled and clarified by centrifugation at $10,000 \times g$ for $10 \mathrm{~min}$. Optical density of the clear supernatants was measured at $533 \mathrm{~nm}$ in UV-Vis spectrophotometer (Systronics, Mumbai,India) employing malondialdehyde as the reference standard (Ernster and Nordenbrand 1967). 
Reduced (GSH) and oxidized (GSSG) forms of glutathione concentrations were measured upon reaction with fluorescent reagent, $o$-phthalaldehyde (OPT) (Hissin and Hilf (1976). Cytosolic extract ( $0.3 \mathrm{ml}$ containing $1.2 \mathrm{mg}$ protein) prepared in buffer B was treated with $60 \mu \mathrm{l}$ of $25 \%$ phosphoric acid and centrifuged at $10,000 \times g$ for $30 \mathrm{~min}$ at $4^{\circ} \mathrm{C}$ to collect clear supernatant. Different aliquots of the supernatant were made up to $0.1 \mathrm{ml}$ with distilled water followed by addition of $1.8 \mathrm{ml}$ of $0.1 \mathrm{M}$ sodium phosphate buffer ( $\mathrm{pH} 8.0)$ containing $5 \mathrm{mM}$ EDTA for glutathione determination. To this, $0.1 \mathrm{ml}$ of $1 \mathrm{mg} / \mathrm{ml}$ fluorescent reagent OPT was added, mixed and incubated at room temperature for $15 \mathrm{~min}$. For GSSG determination, the supernatant (50 $\mu \mathrm{l})$ was incubated with $50 \mu \mathrm{l}$ of $0.1 \mathrm{M} \mathrm{N}$-ethylmaleimide at room temperature for 30 min before its addition to $1.8 \mathrm{ml}$ of $0.1 \mathrm{~N} \mathrm{NaOH}$. To this, $0.1 \mathrm{ml}$ of $1 \mathrm{mg} / \mathrm{ml} \mathrm{OPT} \mathrm{was} \mathrm{added,} \mathrm{mixed} \mathrm{and} \mathrm{incubated}$ at room temperature for $15 \mathrm{~min}$. The fluorescence intensity was measured at $\lambda_{\mathrm{Ex}}=350 \mathrm{~nm}, \lambda_{\mathrm{Em}}=420 \mathrm{~nm}$, respectively in a spectrofluorometer (Perkin-Elmer, LS-3B). Standards ranging from 0 to $2 \mu \mathrm{g}$ for GSSG and $0-10 \mu \mathrm{g}$ for glutathione were evaluated simultaneously.

SOD activity was assayed by measuring the ability of the enzyme to inhibit super-oxide anion-dependent auto oxidation of pyrogallol as described by Marklund and Marklund (1974). To $0.1 \mathrm{ml}$ cytosolic extract ( $400 \mu \mathrm{g}$ protein) prepared in buffer $\mathrm{C}, 0.7 \mathrm{ml}$ of $50 \mathrm{mM}$ Tris $(\mathrm{pH} 8.0)$ and $0.1 \mathrm{ml}$ of $10 \mathrm{mM}$ diethylenetriaminepenta acetic acid were added. To this $0.1 \mathrm{ml}$ of $10 \mathrm{mM}$ pyrogallol was added and the increase in optical density was monitored for 3 min at $420 \mathrm{~nm}$ by UV-Vis spectrophotometer. One unit of SOD represents the amount of enzyme that inhibits $50 \%$ of the rate of auto-

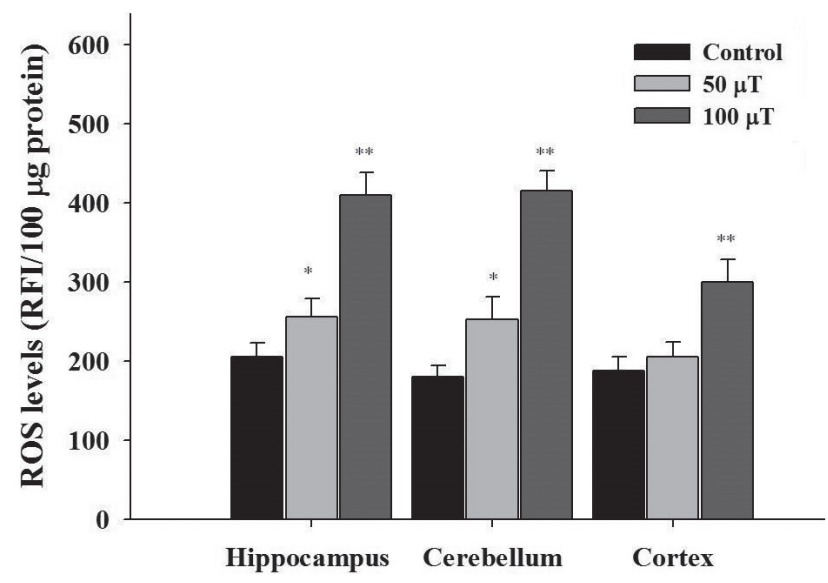

Figure 1. Influence of ELF-MFs on reactive oxygen species accumulation in rat brain. The reactive oxygen species (ROS) accumulation is denoted in terms of relative fluorescence intensity (RFI) in cells corresponding to $100 \mu \mathrm{g}$ protein. ${ }^{\star} p<0.05$ and ${ }^{\star *} p<0.005$ at 50 and $100 \mu \mathrm{T}$ are considered as statistically significant in comparison to sham controls. oxidation of pyrogallol/min/mg protein under the defined assay conditions.

GPx was assayed as per the method of Martinez et al. (1979) involving degradation of cumenehydroperoxide by the enzyme accompanied by oxidation of GSH to GSSG. The reaction mixture (final volume of $1 \mathrm{ml}$ ) containing $100 \mathrm{mM}$ Tris-HCl buffer (pH 8.5) 5 mM EDTA, $100 \mu$ of $100 \mathrm{mM}$ sodium azide, $40 \mu \mathrm{l}$ of $40 \mathrm{mM} \mathrm{GSH}, 100 \mu \mathrm{l}$ of $7 \mathrm{mM}$ cumenehydroperoxide and $25 \mu \mathrm{l}$ of cytosolic extract (100 $\mu \mathrm{g}$ of protein) prepared in buffer $\mathrm{D}$. The reaction mixture was incubated at $37^{\circ} \mathrm{C}$ for $10 \mathrm{~min}$ and the reaction was terminated by the addition of $200 \mu \mathrm{l}$ of $0.1 \mathrm{M} \mathrm{N}$-ethylmaleimide. The contents were mixed thoroughly and incubated at room temperature for $30 \mathrm{~min}$. To this, $2.8 \mathrm{ml}$ of $0.1 \mathrm{M} \mathrm{NaOH}$ was added and $100 \mu \mathrm{l}$ of this reaction mix was assayed for the content of GSSG by addition of $1.8 \mathrm{ml}$ of $\mathrm{NaOH}$ and $100 \mu \mathrm{lof} 1 \mathrm{mg} / \mathrm{ml}$ OPT. The fluorescence of the complex formed between GSSG and OPT was measured at $\lambda_{\mathrm{Ex}}=350 \mathrm{~nm}, \lambda_{\mathrm{Em}}=420 \mathrm{~nm}$ in a spectrofluorometer. One unit of the enzyme activity represents formed GSSG in $\mu \mathrm{g} / \mathrm{min} / \mathrm{mg}$ protein.

\section{Statistical analysis}

Data was analyzed using Jandel Scientific, Sigma Stat Software and all variables are represented as mean \pm SD. Further, data was analyzed by one-way ANOVA followed by Post hoc Duncan's test for multiple comparisons of all parameters determined in present study. Pearson correlation analyses were performed between ROS, TBARS, GSH/GSSG, SOD and GPx (Manikonda et al. 2012). Negative value indicates negative correlation between parameters. The criterion followed for statistical significance was $p \leq 0.05$.

\section{Results}

Long-term exposure of animals to ELF-MF did not cause any change in their body weight, neither were there any differences found upon histopathology (data not shown). However, such exposure resulted in increased physical activity significantly at $50 \mu \mathrm{T}$ and $100 \mu \mathrm{T}(p \leq 0.001)$ compared to sham-exposed controls (previously described in Manikonda et al. 2007). In the present investigation, the changes in oxidative stress markers were perceived in the ELF-MF exposed animals as compared to sham controls, as described below.

\section{ELF-MF exposure caused accumulation of reactive oxygen species}

Long-term (90 days) exposure of ELF-MF $(50 \mathrm{~Hz})$ at 50 and $100 \mu \mathrm{T}$ resulted in increased production of ROS in hippocampus and cerebellum of the brain in a dose-dependent manner as shown in Figure 1. The increments 
were about 24 and $100 \%$ in hippocampus, 40 and 130\% in cerebellum, $9 \%$ and $59 \%$ in cortex, respectively for exposures of 50 and $100 \mu \mathrm{T}$. It may be noted that such increments were statistically much more significant in cerebellum and hippocampus $(p<0.005)$ as compared to cortex.

\section{ELF-MF exposure increased lipid peroxidation}

Determination of TBARS, indicative of membrane damage and lipid peroxidation due to MF exposure, denoted increased lipid peroxidation in all the examined regions, in a dose-dependent manner. Continuous exposure of $100 \mu \mathrm{T}$ ELF-MF resulted in enhanced formation of TBARS, corresponding to $74 \%$ increase in hippocampus $(p<0.005)$, $132 \%$ increase in cerebellum $(p<0.001)$, and $48 \%$ increase $(p<0.005)$ in cortex, as compared to control group. In comparison, cerebellum was shown as more susceptible than hippocampus and cortex to MF intensity of $100 \mu \mathrm{T}$. Further, there was no significant change in lipid peroxidation observed in cortex at $50 \mu \mathrm{T}$ (Figure 2).

\section{ELF-MF exposure altered thiol status}

In order to assess intracellular thiol status, which is related to oxidative stress, relative contents of GSH and GSSG were examined under conditions of MF exposure. Figure 3 depicts the significant decrease of GSH/GSSG ratio in response to MF exposure in a dose-dependent manner in all three regions, although $50 \mu \mathrm{T}$ data points

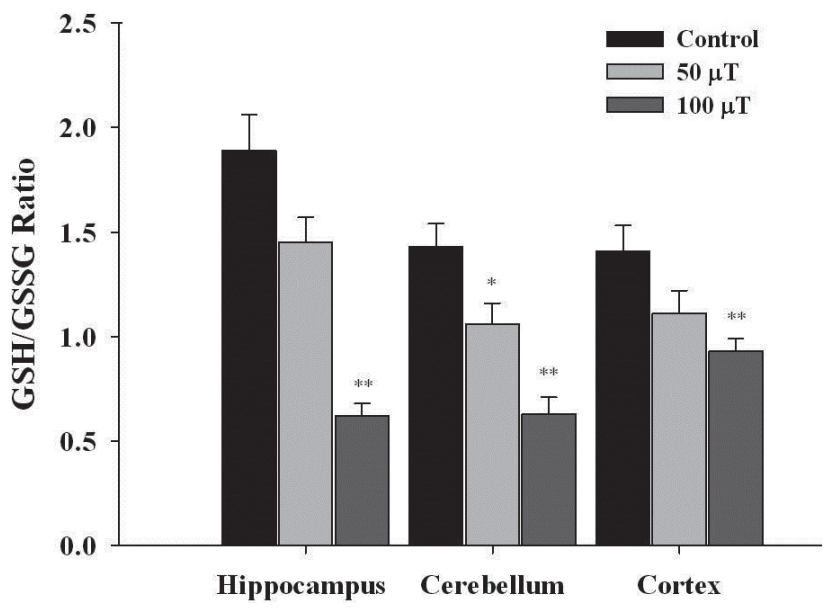

Figure 3. Influence of ELF-MFs on thiol status (GSH/GSSG) in rat brain. ${ }^{*} p<0.05$ and ${ }^{* *} p<0.01$ at 50 and $100 \mu \mathrm{T}$ are considered as statistically significant in comparison to sham controls. GSH, glutathione (reduced); GSSG, glutathione (oxidized).

were not statistically significant from the sham-controls in hippocampus and cortex. Decreased GSH/GSSG ratio was evident in hippocampus (67\%) and cerebellum (56\%) at $100 \mu \mathrm{T}(p<0.001)$. In comparison to the changes observed in all three regions, decrease in GSH/GSSG ratio was much lesser in cortex $(34 \%)$ at $100 \mu \mathrm{T}(p<0.01)$.Furthermore, the total glutathione levels in all three regions were found to be significantly reduced, while GSSG levels were found unaltered in these tissues (data not shown).

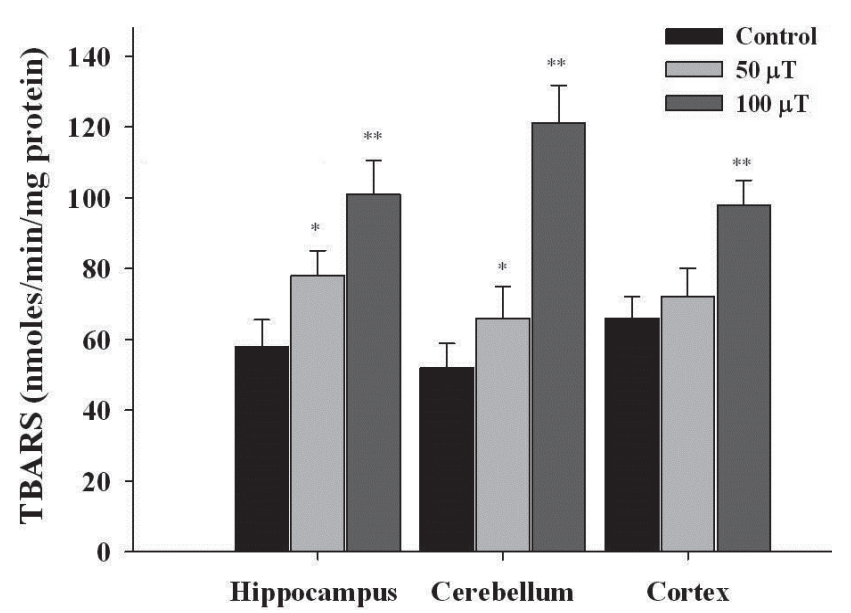

Figure 2. Influence of ELF-MFs on lipid peroxidation in rat brain. Lipid peroxidation levels were measured as TBARS (thiobarbituric acid reactive substances) and values are presented as nmoles $/ \mathrm{min} /$ mg protein. ${ }^{*} p<0.05$ and ${ }^{* *} p<0.005$ at 50 and $100 \mu \mathrm{T}$ are considered as statistically significant in comparison to sham controls.

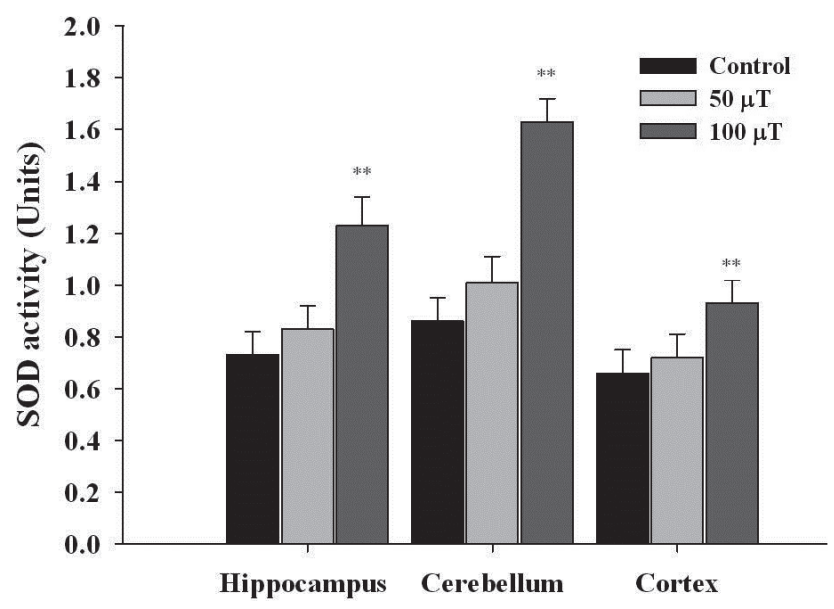

Figure 4. Influence of ELF-MFs on superoxide dismutase (SOD) activity in rat brain. One unit of SOD activity corresponds to $50 \%$ inhibition of pyrogallol auto-oxidation/min/mg protein. ${ }^{* *} p<0.01$ at 50 and $100 \mu \mathrm{T}$ are considered as statistically significant in comparison to sham controls. 
Increased activities of antioxidant enzymes in response to ELF-MF

In order to obtain correlations between oxidative stress and intracellular defenses in response to MF exposure, the activities of antioxidant enzymes viz., SOD and GPx were assayed in three different regions of brain. The SOD activity increased 68\% in hippocampus $(p<0.005), 90 \%$ in cerebel$\operatorname{lum}(p<0.001), 41 \%(p<0.01)$ in cortex for exposure to 100 $\mu \mathrm{T}$ MFs. It may also be noted that activity of this enzyme is not significantly affected in all regions at $50 \mu \mathrm{T}$.

As compared to controls, increased GPx activity could be noticed to occur in a dose-dependent manner in hippocampus and cerebellum in response to MFs (Figure 5). Increase in GPx activity in hippocampus (58\%), cerebellum (43\%) and cortex (42\%) was evident at $100 \mu \mathrm{T}$ MF intensity $(p<0.01)$. It may also be noted that cortical activity of this enzyme is not significantly affected at $50 \mu \mathrm{T}$ by $\mathrm{MF}$ exposure.

Pearson correlation analysis revealed that there is negative correlation between ROS and GSH/GSSG, TBARS and GSH/ GSSG, SOD activity and GSH/GSSG, GPx and GSH/GSSG in all examined brain tissues of control and MF-exposed animals (Figure 6). Further, ROS, TBARS, GPx and SOD are positively correlated with each other in all groups accompanied with the oxidative stress. Except SOD-GSH/GSSG, SOD-GPx, the correlations were statistically significant $(p \leq 0.05)$ in all examined brain regions of control animals. Such correlation coefficient values were decreased in $100 \mu \mathrm{T}$ MF-exposed rats indicated that the correlations between the parameters were disturbed upon MF exposure. In addition,

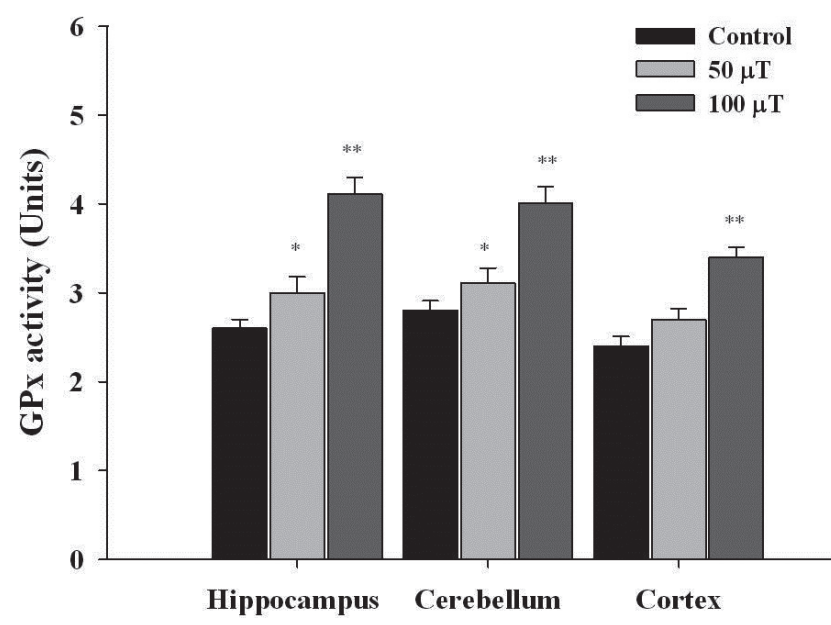

Figure 5. Influence of ELF-MFs on glutathione peroxidase (GPx) activity in rat brain. One unit of the GPx activity corresponds to oxidized glutathione in $\mu \mathrm{g} / \mathrm{min} / \mathrm{mg}$ protein. ${ }^{\star} p<0.05$ and ${ }^{* *} p<0.01$ at 50 and $100 \mu \mathrm{T}$ are considered as statistically significant in comparison to sham controls. correlation coefficient value of ROS-SOD was near to zero $(\mathrm{r}=0.02)$ in $100 \mu \mathrm{T}$ MF exposed rats. A significant negative correlation was observed between TBARS and GSH/GSSG and was retained even in $100 \mu \mathrm{T}$ MF exposure. Further, physical activity of animal was significantly $(p \leq 0.01)$ correlated with ROS $(r=0.975)$, TBARS $(r=0.991)$, GPx $(r=0.979)$ and GSH/GSSG ( $r=-0.939)$, where it was statistically not significant with the activity of SOD $(r=0.669)$ in cerebellum of control animals. Though, there was no significant correlation observed between physical activity and these oxidative stress indicators in 50 and $100 \mu \mathrm{T}$ MF-exposed rats (data not shown).

\section{Discussion and Conclusions}

The primary aim of the present investigation was to evaluate oxidative stress-related parameters occurring in brain upon long-term exposure of rats in response to ELF-MF. Such a study was warranted considering the recognized susceptibility of myelinated nerve fibers to damage due to exposure to MFs (Lai and Singh 2004). Further, the increased risk of power-line workers (frequently exposed to ELF-EMFs) to neuronal diseases such as amyotrophic lateral sclerosis (Zhou et.al. 2012), Alzheimer's disease (Davanipour et al. 2007) and Parkinson's disease (Huss et al. 2002) have prompted these studies. It is well known that neurodegenerative diseases are accompanied with oxidative stress which is modulated through EMF effects, as both pro-oxidant and neuroprotective driving force (Consales et al. 2012; Tasset et al. 2012). Following mechanisms were suggested: (i) EMFs can affect chemical bonds between adjacent atoms with alteration of energy levels and spin orientation of electrons which ultimately promote the generation of free oxygen radicals as $\mathrm{O}_{2}{ }^{-}$and $\mathrm{OH}^{-}$that eventually leads to damage of cellular membranes through lipid peroxidation, and (ii) imbalance of thiol status and DNA damage in addition to alterations in DNA-protein as well as DNA-DNA crosslinks (Ivancsits et al. 2003; Lai and Singh 2004; Yokus et al. 2005). These alterations may depend on energy absorption by the organ and its susceptibility to oxidative damage.

Results obtained in the present investigation supports the earlier observations, which had reported the occurrence of oxidative/nitrosative stress in response to the MF exposure (Li and Chow 2000; Noda et al. 2000; Kabuto et al. 2001; Lee et al. 2004), including effects on cell signaling processes (Liboff et al. 2003; Zhang et al. 2010) and carcinogenic effects (Bayazit et al. 2010). Previous studies suggest that static and time-varying electric and MFs exposure caused oxidative DNA damage (Ivancsits et al. 2003; Yokus et al. 2005), increased plasma, liver, lung and kidney TBARS and SOD levels (Harakawa et al. 2005; Guler 
et al. 2006), decreased GSH levels (Jelenkovic et al. 2005; Di Loreto et al. 2009) altered cell proliferation (Martinez et al. 2012), cortical serotonergic neurotransmission (Janac et al. 2009) and memory impair (Jadidi et al. 2007) in various biological organisms. However, the present study differed from earlier investigations in certain regard, as the present investigation was conducted at much lower magnetic intensities (50 and $100 \mu \mathrm{T}$ ) as compared to the other studies, which were conducted at higher intensities ( 0.1 to $2 \mathrm{mT}$ ). Magnetic intensities for this investigation were chosen on the basis of the results of our national level studies revealing that human exposure to MFs does not exceed 100 $\mu \mathrm{T} /$ day (CPRI report 2000). Further, as opposed to related investigations involving exposure of either cell cultures or tissue slices/homogenates, the present study resorted to exposure of whole body of the animals over prolonged periods. The experimental design also focused on central nervous system, because it contains high concentrations of easily peroxidisable fatty acids, catecholamines, adrenaline, nor-adrenaline and dopamine, which are exceptionally vulnerable to free radical generation (Tabner et al. 2005). Additionally, neuronal cells have high rates of iron intake and enriched mitochondrial content with higher metabolic rates would be more susceptible to the effects of MFs because hydrogen peroxide, the substrate of the Fenton reaction, is a metabolic product of mitochondria (Lai and Singh 2004).

It can be inferred from the present study that continuous exposure of rats to 50 and $100 \mu \mathrm{T}$ ELF-MF results in oxidative stress and altered glutathione levels in a dose- dependent manner in all three regions, although the value $50 \mu \mathrm{T}$ was not significant from the control in the hippocampus
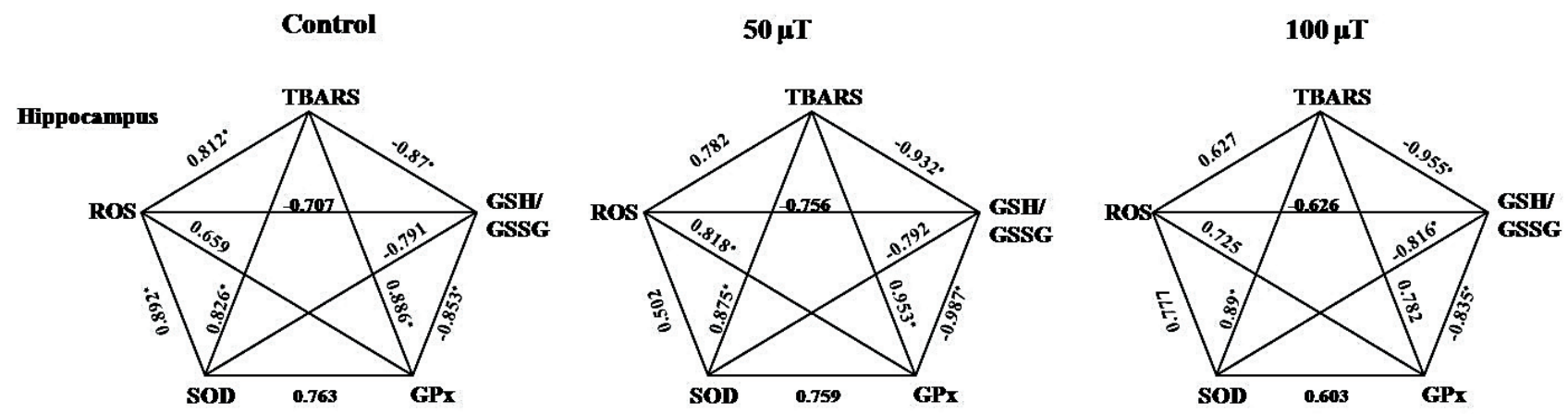

Cerebellum
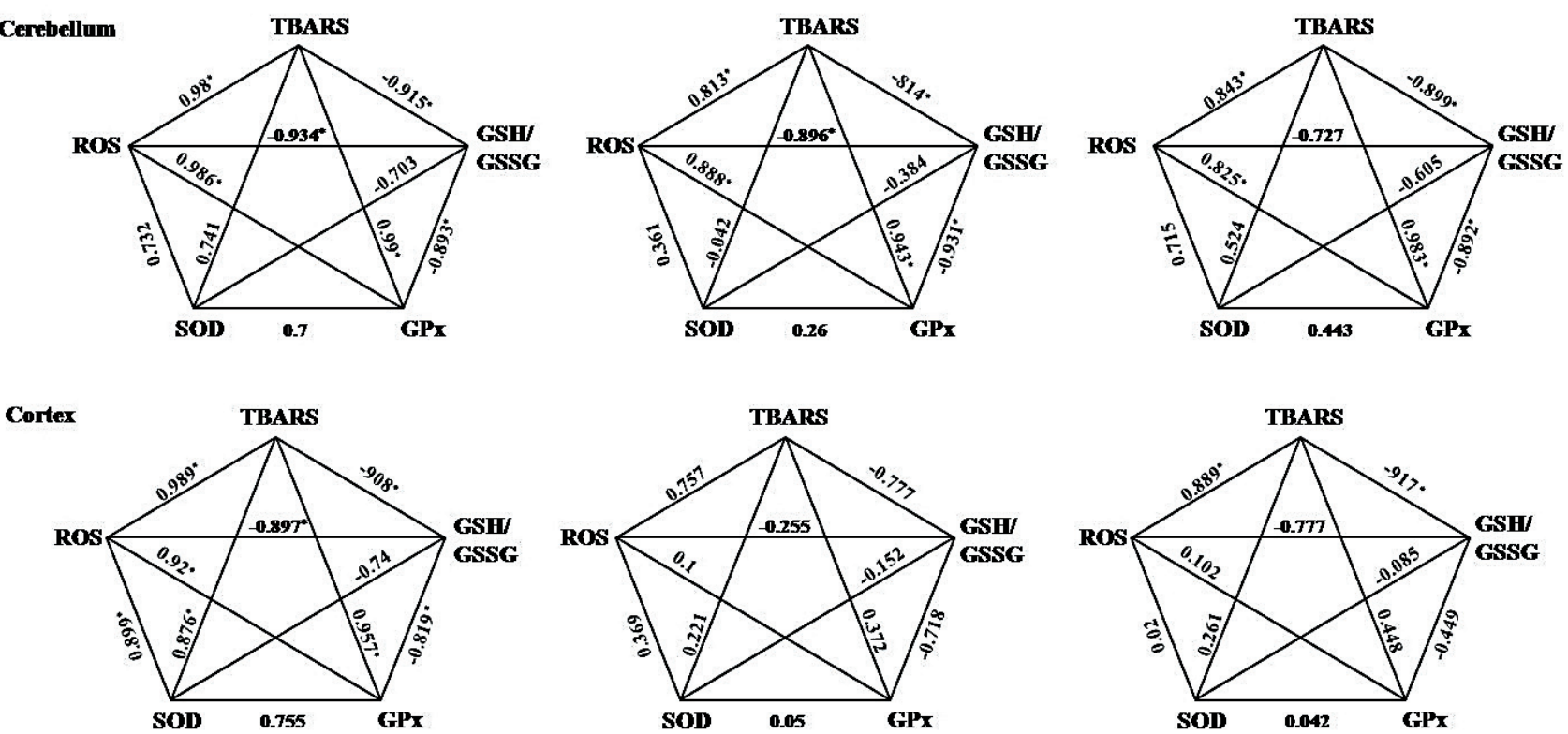

Figure 6. Influence of ELF-MFs on Pearson correlation between oxidative stress indicators. The Pearson correlations between reactive oxygen species (ROS), lipid peroxidation (TBARS), thiol status (GSH/GSSG), activities of superoxide dismutase (SOD) glutathione peroxidase $(\mathrm{GPx})$ in rat brain. Each value is a correlation coefficient value between parameters and the negative value indicates negative correlations between the parameters. ${ }^{*}$ indicates statistically significant value between the parameters $(p \leq 0.05)$. 
and cortex. However, the activity of SOD was found to be significantly increased at $100 \mu \mathrm{T}$ in all regions (but not at $50 \mu \mathrm{T})$. Even though, intracellular mechanisms underlying is unclear, the enhanced intracellular superoxide radicals may mediate the increased SOD activity. On the contrary, few earlier reports are suggestive of decreased SOD and catalase activities in the rat brain exposed to ELF-EMF ( $2 \mathrm{~h} /$ day, 10 months, 100-500 $\mu \mathrm{T}$ ) (Akdag et al. 2010; MartinezSamano et al. 2012) and insignificant increase in oxidative stress parameters ( $4 \mathrm{~h} /$ day, 12 weeks, $100 \mu \mathrm{T}$ ) on hippocampus and striatum in mouse (Cui et al. 2012). In our study, rats exposed to ELF-MF continuously for 90 days (24h/day without gap) exhibited significant changes even at $100 \mu \mathrm{T}$. This aspect can be explained as the degree of consequences that depend on dose and duration of the MF exposure in relation to the status of oxidative stress and antioxidant defense mechanism(s) in the various biological systems. In addition, the present experimental investigation indicated the accumulation of ROS, lipid peroxidation end products and increase of SOD activity in different regions, which are in the descending order of cerebellum $>$ hippocampus $>$ cortex. Decreases in GSH/GSSG ratio as well as in the increase in activity of GPx are in the descending order of hippocampus $>$ cerebellum $>$ cortex.

Pearson correlation analysis indicated that the ROS, lipid peroxidation, GPx and SOD are positively correlated with each other and negatively correlated with GSH/GSSG in all the groups (Figure 6). The significance in correlations between various parameters were observed to decline in rats exposed to $100 \mu \mathrm{T}$ MF as compared to control group. This can be attributed to the elevated free radicals and imbalance in antioxidant defense caused by ELF-MF. The physical activity was also not correlated with oxidative stress indicators in ELF-MF exposed animals. Previous studies denoted that the significant correlations between such parameters were interrupted with age-induced oxidative stress conditions in liver of male Wistar rats (Manikonda et al. 2012) and mice (Muradian et al. 2002). In present study, the correlations between the parameters were less significant in cortex than cerebellum and hippocampus. Herewith, the comparison of the coefficients of correlations suggested that the correlative links between the parameters in the brain of 100 $\mu \mathrm{T}$ MF-exposed rats could be mediated through ELF-MF or other external coordinating factors. The increased oxidative stress observed in different regions of rat brain by ELF-MF exposure, reported here, may contribute to altered metabolic and physiological events in individual regions of the central nervous system, leading to aberrant neuronal functions.

Acknowledgements. This work was supported by contract grant No. 11.1.14 of Central Power Research Institute, Ministry of Power, India.

\section{References}

Ahlbom A., Cardis E., Green A., Linet M., Savitz D., Swerdlow A. (2001): Review of the epidemiologic literature on EMF and health. Environ. Health Perspect. 109, 911-933 http://dx.doi.org/10.2307/3454653

Akdag M. Z., Dasdag S., Ulukaya E., Uzunlar A. K., Kurt M. A., Taskin A. (2010): Effects of extremely low-frequency magnetic field on caspase activities and oxidative stress values in rat brain. Biol. Trace. Elem. Res. 138, 238-249

http://dx.doi.org/10.1007/s12011-010-8615-3

Akerstedt T., Arnetz B., Ficca G., Paulsson L. E., Kallner A. (1999): A $50 \mathrm{~Hz}$ electromagnetic field impairs sleep. J. Sleep Res. 8, $77-81$ http://dx.doi.org/10.1046/j.1365-2869.1999.00100.x

Bayazit V., Bayram B., Pala Z., Atan O. (2010): Evaluation of carcinogenic effects of electromagnetic fields. Bosn. J. Basic Med. Sci. 10, 245-250

Blank M., Goodman R. (2009): Electromagnetic fields stress living cells. Pathophysiology 16, 71-78

http://dx.doi.org/10.1016/j.pathophys.2009.01.006

Bradford M. M. (1976): A rapid and sensitive method for the quantitation of microgram quantities of protein utilizing the principle of protein dye-binding method. Anal. Biochem. 72, 248-254

http://dx.doi.org/10.1016/0003-2697(76)90527-3

Burch J. B., Reif J. S., Yost M. G., Keefe T. J., Pitrat C. A. (1999): Reduced excretion of a melatonin metabolite in workers exposed to $60 \mathrm{~Hz}$ magnetic fields. Am. J. Epidemiol. 150, 27-36 http://dx.doi.org/10.1093/oxfordjournals.aje.a009914

Central Power Research Institute (CPRI) - Final Technical Report 2000, Identification No. 11.1.11, Ultra High Voltage Research Laboratory, CPRI, Ministry of Power, Government of India

Chu L. Y., Lee J. H., Nam Y. S., Lee Y. J., Park W. H., Lee B. C., Kim D., Chung Y. H., Jeong J. H. (2011): Extremely low frequency magnetic field induces oxidative stress in mouse cerebellum. Gen. Physiol. Biophys. 30, 415-421 http://dx.doi.org/10.4149/gpb_2011_04_415

Ciejka E., Kleniewska P., Skibska B., Goraca A. (2011): Effects of extremely low frequency magnetic field on oxidative balance in brain of rats. J. Physiol. Pharmacol. 62, 657-661

Consales C., Merla C., Marino C., Benassi B. (2012): Electromagnetic fields, oxidative stress and neurodegeneration. Int. J. Cell Biol. 2012, 683897 doi:10.1155/2012/683897 http://dx.doi.org/10.1155/2012/683897

Cui Y., Ge Z., Rizak J. D., Zhai C., Zhou Z., Gong S., Che Y. (2012): Deficits in water maze performance and oxidative stress in the hippocampus and striatum induced by extremely low frequency magnetic field exposure. PLoS One 7, e32196 http://dx.doi.org/10.1371/journal.pone.0032196

Davanipour Z., Tseng C. C., Lee P. J. Sobel E. (2007): A case control study of occupational magnetic field exposure and Alzheimer's disease: results from the California Alzheimer's disease diagnosis and treatment centers. BMC Neurology 7, 13 http://dx.doi.org/10.1186/1471-2377-7-13

Davis S., Mirick D. K., Chen C., Stanczyk F. Z. (2006): Effects of 60-Hz magnetic field exposure on nocturnal 6-sulfatoxymelatonin, estrogens, luteinizing hormone, and follicle-stimulating 
hormone in healthy reproductive-age women: results of a crossover trial. Ann. Epidemiol. 16, 622-631 http://dx.doi.org/10.1016/j.annepidem.2005.11.005

Di Loreto S., Falone S., Caracciolo V., Sebastiani P., D‘Alessandro A., Mirabilio A., Zimmitti V., Amicarelli F. (2009): Fifty hertz extremely low-frequency magnetic field exposure elicits redox and trophic response in rat-cortical neurons. J. Cell Physiol. 219, 334-343 http://dx.doi.org/10.1002/jcp.21674

Driver A. S., Kodavanti P. S., Mundy W. R. (2000): Age related changes in reactive oxygen species production in rat brain homogenates. Neurotoxicol.Teratol. 22, 175-181 http://dx.doi.org/10.1016/S0892-0362(99)00069-0

Electric and Magnetic Field Research and Public Information Dissemination (EMF RAPID) Program, NIEHS (2004)

El-Helaly M., Abu-Hashem E. (2010): Oxidative stress, melatonin level, and sleep insufficiency among electronic equipment repairers. Indian J. Occup Environ. Med. 14, 66-70 http://dx.doi.org/10.4103/0019-5278.75692

Ernster L., Nordenbrand K. (1967): Microsomal lipid peroxidation. Met. Enzymol. 10, 574-580 http://dx.doi.org/10.1016/0076-6879(67)10099-2

Falone S., Mirabilio A., Carbone M. C., Zimmitti V., Di Loreto S., Mariggio M. A., Mancinelli R., Di Ilio C., Amicarelli F. (2008): Chronic exposure to $50 \mathrm{~Hz}$ magnetic fields causes a significant weakening of antioxidant defence systems in aged rat brain. Int. J. Biochem. Cell Biol. 40, 2762-2770 http://dx.doi.org/10.1016/j.biocel.2008.05.022

Fu Y., Wang C., Wang J., Lei Y., Ma Y. (2008): Long-term exposure to extremely low-frequency magnetic fields impairs spatial recognition memory in mice. Clin. Exp. Pharmacol. Physiol. $35,797-800$ http://dx.doi.org/10.1111/j.1440-1681.2008.04922.x

Funk R. H. W., Monsees T., Ozkucur N. (2009): Electromagnetic effects - From cell biology to medicine. Progr. Histochem. Cytochem. 43, 177-264 http://dx.doi.org/10.1016/j.proghi.2008.07.001

Foroozandeh E., Derakhshan-Barjoei P., Jadidi M. (2013): Toxic effects of $50 \mathrm{~Hz}$ electromagnetic field on memory consolidation in male and female mice. Toxicol. Ind. Health. 29, 293-299 http://dx.doi.org/10.1177/0748233711433931

Guler G., Seyhan N., Aricioglu A. (2006): Effects of static and 50 $\mathrm{Hz}$ alternating electric fields on superoxide dismutase activity and TBARS levels in guinea pigs. Gen. Physiol. Biophys. 25, 177-193

Harakawa S., Inoue N., Hori T., Tochio K., Kariya T., Takahashi K., Doge F., Suzuki H., Nagasawa H. (2005): Effects of $50 \mathrm{~Hz}$ electric field on plasma lipid peroxide level and antioxidant activity in rats. Bioelectromagnetics 26, 589-594 http://dx.doi.org/10.1002/bem.20137

Hissin P., Hilf R. A. (1976): Flourimetric method for determination of oxidized and reduced glutathione in tissues. Anal. Biochem. 74, 214-226 http://dx.doi.org/10.1016/0003-2697(76)90326-2

Huss A., Spoerri A., Egger M., Roosli M. (2009): Residence near power lines and mortality from neurodegenerative diseases: longitudinal study of the Swiss population. American J. Epidemiol. 169, 167-175 http://dx.doi.org/10.1093/aje/kwn297

Ivancsits S., Diem E., Jahn O., Rudiger H. W. (2003): Intermittent extremely low frequency electromagnetic fields cause DNA damage in a dose-dependent way. Int. Arch. Occup. Environ. Health 76, 431-436 http://dx.doi.org/10.1007/s00420-003-0446-5

Jadidi M., Firoozabadi S. M., Rashidy-Pour A., Sajadi A. A., Sadeghi H., Taherian A. A. (2007): Acute exposure to a $50 \mathrm{~Hz}$ magnetic field impairs consolidation of spatial memory in rats. Neurobiol. Learn. Mem. 88, 387-392 http://dx.doi.org/10.1016/j.nlm.2007.07.010

Janac B., Tovilovic G., Tomic M., Prolic Z., Radenovic L. (2009): Effect of continuous exposure to alternating magnetic field (50 $\mathrm{Hz}, 0.5 \mathrm{mT}$ ) on serotonin and dopamine receptors activity in rat brain. Gen. Physiol. Biophys. 28, 41-46

Jelenkovic A., Janac B., Pesic V., Jovanovic M. D., Vasiljevic I., Prolic Z. (2005):The effects of exposure to extremely low-frequency magnetic field and amphetamine on the reduced glutathione in the brain. Ann. NY. Acad. Sci. 1048, 377-380

http://dx.doi.org/10.1196/annals.1342.044

Kabuto H., Yokoi I., Ogawa N., Mori N., Liburdy R. P. (2001): Effects of magnetic fields on the accumulation of thiobarbituric acid reactive substances induced by iron salt and $\mathrm{H} 2 \mathrm{O} 2$ in mouse brain homogenates or phosphotidylcholine. Pathophysiology 7, 283-288

http://dx.doi.org/10.1016/S0928-4680(00)00062-6

Kerman M., Senol N. (2012): Oxidative stress in hippocampus induced by $900 \mathrm{MHz}$ electromagnetic field emitting mobile phone: Protection by melatonin. Biomed. Res. 23, 147-151

Kheifets L., Bowman J. D., Checkoway H., Feychting M., Harrington J. M., Kavet R., Marsh G., Mezei G., Renew D. C., van Wijngaarden E. (2009): Future needs of occupational epidemiology of extremely low frequency electric and magnetic fields: review and recommendations. Occup. Environ. Med. 66, 72-80 http://dx.doi.org/10.1136/oem.2007.037994

Lai H., Singh N. P. (2004): Magnetic field induced DNA strand breaks in brain cells of the rat. Environ. Health Perspect. 112, 687-694 http://dx.doi.org/10.1289/ehp.6355

Lee B. C., Johng H. M., Lim J. K., Jeong J. H., Baik K. Y., Nam T. J., Lee J. H., Kim J., Sohn U. D., Yoon G., Shin S., Soh K. S. (2004): Effects of low frequency magnetic field on the antioxidant defense system in mouse brain: a chemiluminescence study. J. Photochem. Photobiol. Biol. 73, 43-48 http://dx.doi.org/10.1016/j.jphotobiol.2003.10.003

Li S. H., Chow K. C. (2001): Magnetic field exposure induces DNA degradation. Biochem. Biophys. Res. Commun. 280, 1385-1388 http://dx.doi.org/10.1006/bbrc.2001.4286

Liboff A. R., Cherng S., Jenrow K. A., Bull A. (2003): Calmodulin-dependent cyclic nucleotide phosphodiesterase activity is altered by $20 \mu \mathrm{T}$ magnetostatic fields. Bioelectromagnetics 24, 32-38 http://dx.doi.org/10.1002/bem.10063

Manikonda P. K., Jagota A. (2012): Melatonin administration differentially affects age-induced alterations in daily rhythms of lipid peroxidation and antioxidant enzymes in male rat liver. Biogerontol. 13, 511-524 
http://dx.doi.org/10.1007/s10522-012-9396-1

Manikonda P. K., Rajendra P., Devendranath D., Gunasekaran B., Channakeshava, Aradhya R. S. S., Sashidhar R. B., Subramanyam C. (2007): Influence of extremely low frequency of magnetic fields on Ca2+-signaling and NMDA receptor functions in rat hippocampus. Neurosci. Lett. 413, 145-149 http://dx.doi.org/10.1016/j.neulet.2006.11.048

Marklund S., Marklund G. (1974): Involvement of superoxide anion radical in the auto oxidation of pyrogallol and a convenient assay for superoxide dismutase. Eur. J. Biochem. 47, 469474http://dx.doi.org/10.1111/j.1432-1033.1974.tb03714.x

Martinez J. I. R., Launay J. M., Dreux C. (1979): A sensitive fluorimetric assay for glutathione activity: Application to human blood platelets. Anal. Biochem. 98, 154-159 http://dx.doi.org/10.1016/0003-2697(79)90720-6

Martinez M. A., Ubeda A., Cid M. A., Trillo M. A. (2012): The proliferative response of NB69 human neuroblastoma cells to a $50 \mathrm{~Hz}$ magnetic field is mediated by ERK1/2 signaling. Cellular Physiol. Biochem. 29, 675-686 http://dx.doi.org/10.1159/000178457

Martinez-Samano J., Torres-Duran P. V., Juarez-Oropeza M. A., Verdugo-Diaz L. (2012): Effect of acute extremely low frequency electromagnetic field exposure on the antioxidant status and lipid levels in rat brain. Arch. Medical Res. 43, 183-189 http://dx.doi.org/10.1016/j.arcmed.2012.04.003

Muradian K. K., Utko N. A., Fraifeld V., Mozzhukhina T. G., Pishel I. N., Litoshenk A. Y. (2002): Superoxide dismutase, catalase and glutathione peroxidase activities in the liver of young and old mice: linear regression and correlation. Arch. Gerontol. Geriat. 35, 205-214 http://dx.doi.org/10.1016/S0167-4943(02)00025-0

Noda Y., Mori A., Liburdy R. P., Packer L. (2000): Pulsed magnetic fields enhance nitric oxide synthase activity in rat cerebellum. Pathophysiology 7, 127-130 http://dx.doi.org/10.1016/S0928-4680(00)00039-0

Pandi-Perumal S. R., Bahammam A. S., Brown G. M., Spence D. W., Bharti V. K., Kaur C., Hardeland R., Cardinali D. P. (2013): Melatonin antioxidative defense: Therapeutical implications for aging and neurodegenerative processes. Neurotox. Res. 23, 267-300 http://dx.doi.org/10.1007/s12640-012-9337-4

Rajendra P., Sujatha H. N., Devendranath D., Gunasekaran B., Sashidhar R. B., Subramanyam C., Channakeshava (2004): Biological effects of power frequency magnetic fields: Neurochemical and toxicological changes in developing chick embryos. BMC-Biomag. Res. and Technol. 2, 1-9

Rajendra P., Sujatha H. N., Sashidhar R. B., Subramanyam C., Devendranath D., Gunasekaran B., Aradhya R. S. S., Bhaskaran A. (2005): Effects of power frequency electromagnetic fields on growth of germinating Viciafaba L., the broad bean. Electromag. Biol. Med. 24, 39-54

http://dx.doi.org/10.1081/JBC-200055058
Rajendra P., Sujatha H. N., Sashidhar R. B., Subramanyam C., Devendranath D., Aradhya R. S. S. (2012): Extremely low frequency electromagnetic field enhances the viability of unstimulated lymphocytes. BioDiscovery 2, 1

Sokolovic D., Djindjic B., Nikolic J., Bjelakovic G., Pavlovic D., Kocic G., Krstic D., Cvetkovic T., Pavlovic V. (2008): Melatonin reduces oxidative stress induced by chronic exposure of microwave radiation from mobile phones in rat brain. J. Radiat. Res. 49, 579-586 http://dx.doi.org/10.1269/jrr.07077

Stevens R. G. (2004): Electromagnetic fields and free radicals. Environ. Health Perspect. 112, 687-694 http://dx.doi.org/10.1289/ehp.112-a726a

Schuz J., Ahlbom A. (2008): Exposure to electromagnetic fields and the risks of childhood leukemia. Radiat. Prot. Dosimetry 132, 202-211 http://dx.doi.org/10.1093/rpd/ncn270

Tabner B. J., El-Agnaf O. M., German M. J., Fullwood N. J., Allsop D. (2005): Protein aggregation, metals and oxidative stress in neurodegenerative diseases. Biochem. Soc. Trans. 33, 1082-1086 http://dx.doi.org/10.1042/BST20051082

Tasset I., Medina F. J., Jimena I., Aguera E., Gascon F., Feijoo M., Sanchez-Lopez F., Luque E., Pena J., Drucker-Colin R., Tunez I. (2012): Neuroprotective effects of extremely low-frequency electromagnetic fields on a Huntington's disease rat model: effects on neurotrophic factors and neuronal density. Neurosci. 209, 54-63 http://dx.doi.org/10.1016/j.neuroscience.2012.02.034

World Health Organization (2007): Electromagnetic fields and public health: Exposure to extremely low frequency fields. Fact sheet No. 322

Yokus B. C., Cakir D. U., Akdag M. Z., Sert C., Mete N. (2005): Oxidative DNA damage in rats exposed to extremely low frequency electromagnetic fields. Free Radic. Res. 39, 317-323 http://dx.doi.org/10.1080/10715760500043603

Zhang X., Liu X., Pan L., Lee I. (2010): Magnetic fields at extremely low-frequency $(50 \mathrm{~Hz}, 0.8 \mathrm{mT})$ can induce the uptake of intracellular calcium levels in osteoblasts. Biochem. Biophys. Res. Commun. 396, 662-666 http://dx.doi.org/10.1016/j.bbrc.2010.04.154

Zhou H., Chen G., Chen C., Yu Y., Xu Z (2012): Association between extremely low-frequency electromagnetic fields occupations and amyotrophic lateral sclerosis: A meta-analysis. PLoS One 7, e48354 http://dx.doi.org/10.1371/journal.pone.0048354

Zwirska-Korczala K., Adamczyk-Sowa M., Polaniak R., Sowa P., Birkner E., Drzazga Z., Brzozowski T., Konturek S. J.(2004): Influence of extremely-low-frequency magnetic field on antioxidative melatonin properties in AT478 murine squamous cell carcinoma culture. Biol. Trace Elem. Res. 102, 227-243 http://dx.doi.org/10.1385/BTER:102:1-3:227

Received: January 25, 2013

Final version accepted: July 15, 2013 